\title{
Research on Modern Service Industry and New Urbanization Construction in Jilin Province
}

\author{
Yu Guang, Ye Yupeng
}

Changchun University of Finance and Economics, Changchun China, 130122

Keywords: Jilin Province; modern service industry; new urbanization; construction research

\begin{abstract}
This paper focuses on the modern service industry and new urbanization construction in Jilin Province. By analyzing the concepts, linkages, and development indicators of the two, this paper explores measures to promote the development of modern service industries and new-type urbanization in Jilin Province, and promote their further development and boost economic development.
\end{abstract}

\section{Introduction}

The development of Jilin Province mainly depends on agriculture and heavy industry. With the need for strategic shift in economic development, heavy industry will gradually withdraw. In order to promote sustainable economic development, new economic development strategies must be studied and proposed.By strengthening the emphasis on the modern service industry and combining the needs of the new urbanization construction, we will continue to improve our development strategy and implement it in a timely manner so as to promote the Jilin Province's economy to achieve new development and progress.

\section{Study on the Theory of Modern Service Industry and New Urbanization}

With the development of a modern economy, in addition to traditional agriculture and industry, the service industry has also gradually developed as an important part of the tertiary industry. Under the continuous development of economic globalization, the competition among countries has also gradually changed. In addition to the primary industry and the secondary industry, the competition for the tertiary industry has also become increasingly fierce. In particular, the modern service industry has played a role in the composition of national GDP. The modern service industry is developed based on network technology. The traditional service industry has received information and technology in a timely manner in the new era and applied it to the service development process. It has also become an important part of the modern service industry. The development of science and technology has also led to the development of new service industries and has played an important role in the process of social development.From the analysis of the current economic development trend, the rate of increase in economic output is basically similar to the "Petty-Clark Theorem", that is, with the application of new types of agricultural and industrial production tools and technologies, more people will be released from the primary industry and the secondary industry, and will be engaged in the tertiary industry. This is one of the reasons why the modern service industry has made outstanding contributions to social and economic development. By emphasizing the development of modern service industry, it can provide a large number of employment opportunities and reduce social problems, while creating greater social benefits and promoting social development. At the same time, economic development has gradually stimulated people's material needs, which determines that the tertiary industry will gradually realize new development. However, the corresponding problem is that the modern service industry still has certain problems in the improvement of the overall quality of the labor force, and the growth rate of the employees themselves is relatively slow.

With the rapid development of society and economy, the labor force needed for agricultural development has been greatly reduced, and a large amount of labor has been invested in the 
secondary and tertiary industries. This makes it easier to form clusters of people. The pace of economic and other development in the regions where they live is markedly accelerated, and the people's lives are gradually shifting towards urbanization. This is called a new type of urbanization. Compared with urbanization, new urbanization has significantly strengthened the sustainability of urban development, and has paid more attention to people's livelihood. It can effectively promote social and economic development and improve people's living standards. With the rapid development of new urbanization, the ecological problems in the process of its development can also be gradually solved. This is a high-quality way of urbanization development. The new urbanization development method can gradually change the way people live and travel, choose more ways such as green transportation, and the energy consumption generated in life is also significantly reduced. We can gradually achieve the goal of harmonious coexistence between man and nature, promote the green development of urban development, and then improve people's quality of life.

The development of new urbanization is based on the accumulation of people, and the development of the tertiary industry is an important reason for attracting large-scale populations. With large populations, the development of new urbanization has become possible, and urbanization has stimulated the development of modern service industry, promoted its continuous development and innovation, and provided higher quality through the introduction of new service industries and service technologies. Service. Under such a virtuous cycle, the market environment for urbanization will continue to improve, and the number of people participating in the new urbanization will gradually increase, thus accelerating the pace of development of new urbanization.

Index design and comprehensive evaluation of modern service industry in Jilin Province

The development of modern service industry is a major trend of the times and plays an important role in social and economic development. The current direction of economic development is the shift of the large-scale labor force to the tertiary industry. The proportion of the modern service industry in the national economy should also continue to rise.At the same time, a variety of emerging technologies have also been applied in the development of the modern service industry, and there should be some differences in the market share they should occupy. By establishing the turnover of the technology market of modern service industry, it is possible to establish relatively clear goals for the development of modern service industry and promote the smooth development of the work according to plan. Under this premise, the development of related financial industry and other indicators of the development level can effectively promote the modern service industry to achieve further development and improve the overall quality of modern services in Jilin Province. For this reason, the relevant departments in Jilin Province must strengthen the emphasis on the investment in modern service industries. By adjusting the investment in fixed assets and the increase in spending on science, education and culture, the financial industry will be promoted to achieve further development, thereby achieving the increase in various indicators of the modern service industry.

Jilin Province's modern service industry development plans and indicators are also continuously improving, which is of great significance for promoting the development of related industries. After comprehensive consideration of various indicators of economic development, it can be found that the growth potential of the modern service industry in Jilin Province in terms of development potential, as well as input and final revenue has been relatively more significant, and has an important impact on promoting its further development. At the same time, its development shocks during the economic crisis and other time periods have accumulated rich experience for its follow-up related construction, which is conducive to a better and faster development of the modern service industry.

\section{New Urbanization Development Indicators and Comprehensive Evaluation in Jilin Province}

The development indicators of new urbanization can be mainly described in the following three aspects. The first is the people's livelihood. The development of new-type urbanization is based on 
the clustering of people. It is necessary to strengthen the emphasis on the quality of life of residents. By formulating a reasonable development plan, the per capita income of urban residents can be increased. At the same time, by adjusting the city's development plan and infrastructure construction, residents can easily travel and seek medical care, providing residents with a better quality of life. The urban-rural duality structure is an important factor affecting the new-type urbanization construction. It is necessary to strengthen the emphasis on the urban-rural dual structure coefficient, and accelerate the comprehensive development of cities and towns, reduce the index coefficient, and narrow the development gap between urban and rural areas. Second, we should get rid of the problem of only focusing on economic development and ignoring sustainable development in the process of traditional urbanization. By strengthening the importance of coal reserves, etc., a reasonable development plan is formulated. We will vigorously develop the modern service industry and the Internet industry, and promote the universal adoption of the Internet. At the same time, large-scale tree planting and afforestation will ensure the ecological effects of urbanization and promote its scientific development and realization of sustainable development goals. Finally, we attach importance to the implementation of the policy. Further emphasize the city's green area ratio and proportion of waste disposal, etc., to improve the utilization of various energy sources, speed up the pace of urbanization, reduce the urban-rural gap, and accelerate the speed of urbanization. The examination of various inspection indicators such as Analytic Hierarchy Process (AHP) and consistency check shows that the speed of new urbanization has accelerated significantly, but there are still certain deficiencies in the construction of people's livelihood. Relevant departments should strengthen the importance attached to the prevention of economic crisis, promote the smooth progress of various tasks in accordance with the plan, and adjust the current stagnation of the development of new urbanization in Jilin Province and promote its realization of new development.

\section{Measures to Promote the Development of Modern Service Industry and New Urbanization in Jilin Province}

Space agglomeration is an important reason for the development of new urbanization. Relevant departments must strengthen the emphasis on spatial agglomeration in different industries and promote the smooth development of urbanization through the promotion of agglomeration of different industries and the formation of unique agglomeration effects. Industrial agglomeration has played an important role in providing comprehensively optimized services by strengthening the links between different industries. The timely exchange of information, resources, and services among industries can help improve the effectiveness of industrial agglomeration in the same region and bring them closer to the outside world. The external economic effects of the region can be maximized. At the same time, under the condition that the industry is highly agglomerated, the intensive type of development and the efficiency of resource utilization have been significantly improved. With proper assistance from the government, regional businesses can be quickly established. On this basis, the expansion of the real estate industry, the health care industry, and the education industry will form new towns. This is of great significance in accelerating the development of new urbanization. Relevant departments must pay more attention to industrial agglomeration and other work within the region, integrate the conditions for agglomeration formed by cities and towns as far as possible, promote the smooth progress of various tasks in accordance with the plan, and increase the efficiency of new urbanization construction in Jilin Province.

In terms of the current situation of urbanization construction in Jilin Province, it is necessary to use the external diffusion method as far as possible, start from the central city and gradually penetrate into the surrounding areas, promote its acceptance of advanced ideas and construction theories of the central city, and promote the development of the surrounding areas.The development quality and strength of the central cities have an important influence on the final effect of the drip effect. It is necessary to strengthen the construction of the central city, and on this basis, co-ordinate the problems existing in the development of different regions, and promote the smooth development of all work according to the planned plan. To achieve the goal of regional overall development and 
accelerate the construction of new urbanization. Therefore, relevant departments in Jilin Province must strengthen the emphasis on industrial transformation and upgrading. Based on the top-level design, it is necessary to accelerate the pace of industrial transfer, vigorously develop the tertiary industry, increase the per capita income of residents in various regions, and use the radiation effects of the central city to promote its development in the new round of urbanization.

The modern service industry is mainly composed of new industries driven by science and technology and traditional service industries that accept new technological transformations. With the rapid development of the knowledge economy, we must strengthen the emphasis on knowledge information in the development of modern service industry. By adjusting the service industry structure in Jilin Province, it is necessary to increase support for knowledge and information services.By increasing investment in scientific and technological information, a new strategy for the introduction and training of strategic talents will be formulated, and its role in the regional economic development process will be brought into play, and all work will be smoothly carried out as planned. Improve the quality and speed of modern service industry development and increase its share of the economic structure of Jilin Province.

\section{Conclusion}

Modern service industry and new-type urbanization construction are two of the two key directions in the development of Jilin Province. Relevant departments must pay attention to the existing problems and development indicators. By comprehensively considering the connection between each other, relevant constructions should be carried out rationally. Accelerate the pace of modern service industry and new urbanization in Jilin Province, and promote economic development.

\section{Acknowledgment}

Project : "The 13th Five-Year Plan" Social Science Project of the Education Department of Jilin Province - Research on modern service industry and new urbanization construction in Jilin Province (No. JJKH20171017SK).

\section{References}

[1] Jing Ran, Ge ZiWai. Research on the Coordinated Development of New Urbanization and Modern Service Industry in Jilin Province [J]. Journal of Hubei University of Economics (Humanities and Social Sciences), 2017, (10): 20-22.

[2] Zhu Wanchun. How can new urbanization and modern service industry merge and develop [J].People's Forum, 2017, (31):84-85.

[3] Li Xiaobin. Research on the Driving Mechanism of New Urbanization Promoted by Industrial Transformation and Upgrading [J].TruthSeeking, 2015, (2):59-64. 